\title{
Experimental Evaluation of Dental Implant Biome- chanics Given Certain Stages of the Fixing Substrate Deterioration by Video Image Correlation Method
}

\author{
Száva Dániel Tamás ${ }^{\star}$, Száva loan², Gálfi Botond², lacob Alina , Petrovan Cecilia ${ }^{1}$, Ormenișan Alina ${ }^{1}$, \\ Székely Melinda 3 \\ Department of Oral and Maxillofacial Surgery, Faculty of Dental Medicine, University of Medicine and Pharmacy, Tîrgu Mureș, România \\ 2 University of Transilvania, Faculty of Mechanical Engineering, Brașov, România \\ ${ }^{3}$ Department of Morphology of The Teeth, Faculty of Dental Medicine, University of Medicine and Pharmacy, Tîrgu Mureș, România
}

\begin{abstract}
Background: Dental implants are useful tools and represent a widely spread technique for oral rehabilitation. Their long standingness is highly influenced by the mechanical and geometrical properties of the surrounding osseous tissue in which they are placed. In some unsuccessful cases though, the dental implant is exposed to masticatory forces and other functional acts, and osseous tissue may resorb near its vicinity, leading to the dental implants loss. We investigated the strain distribution inside the fixating substrate, given certain stages of its deterioration near the dental implants.

Material and methods: For our investigations we used cilindro-conical screw-type dental which were submitted to vertical forces between 0-1000 N. The dental implants were fixed inside a plastic material used in photo-elastic measurements.

To evaluate the strain distribution inside the fixing substrate, we used a non-contact, experimental investigation tool, the Video Image Correlation (VIC-3D) optical system. This system allows the implementation in the dental implants optimisation from stress-strain state point of view. Results: The strain field distribution inside the fixating substrate was measured at three different levels of the dental implant, when it was loaded alone and in the case when there were loaded two dental implants simultaneously.

Conclusions: The most stresses are concentrated in the neck-area of the dental implant. If there are loaded two or more dental implants simultaneously, the distance between them influences strain distribution. The measurements were conducted in vitro and do not represent the in vivo conditions, but serve further important facts regarding biomechanical properties of dental implants.
\end{abstract}

Keywords: dental implant, Video Image Correlation, strain-field, fixing substrate deterioration

Received: 09 December 2014 / Accepted: 04 June 2015

\section{Introduction}

Dental implantology has an important role in the act of healing in dental care. However it is not an absolute necessity in prostethic dentistry and oral rehabilitation of our patients, yet it is becoming more and more used and adopted by dentists. Dental implants in their functional phase transmit the masticatory forces to the surrounding fixating substrate (mandibular/maxillar bone). The implant's durability depends on the vertical and horizontal quantity of the surrounding bone. The functionally triggered forces which affect the intra-oral part of the dental implant will strain the fixing substrate in different measures. Being exposed to masticatory forces and other functional acts, osseous tissue may begin to resorb and small amount of bone loss appears around the dental implant, approximately $0.5 \mathrm{~mm}$ during the first postsurgical year and thereafter 0.06 to $0.08 \mathrm{~mm}$ annually [1]. In unsuccessful cases due to peak tensions, higher than $100-150 \mathrm{Mpa}$ in case of cortical bone and $30 \mathrm{Mpa}$ in case of spongious bone [2,3], which increase the rate of bone resorption, [4] and lead to dental implant failure [5]. In our research we

* Correspondence to: Dániel Tamás Száva

E-mail: szavadani@yahoo.com studied the bio-mechanical phenomena and strain distribution inside the fixing substrate, given certain stages of its deterioration surrounding the dental implant. We examined further the biomechanical phenomenons and strain distribution given two implants with different horizontal distances between them.

\section{Material and methods}

In our study we used cylindrical- conical screw- type implants from Protetim Plus, Hungary.

These were inserted partially in the fixating substrate as far as the last cervical fillet in order to simulate deterioration of the fixing substrate. The fixating substrate was made of a plastic material Araldite D, generally used in photo-elastic measurements. We chosed this material because of its resistance and homogeneity, which ensure optimal measuring circumstances. The dental implants were subjected to axial compressive forces from 0 to $1000 \mathrm{~N}$. In response, the fixating substratee formation, and strains inside the fixating substrate appeared and relative displacements could be measured [6].

In order to observe and measure these strains, we used the digital image correlation method (DIC/VIC). This optical investigational method does not need contact with 
the surface of the examined piece, respectively it is independent of its material. In consequence, it does not intervene in the modification process of the examined field of displacement and deformation of the structure thanks to external factors (such as mechanical or thermal influences) or internal ones (such as modification of the crystalline structure etc.); it can be applied to a large sort of materials (homogeny, un-homogeny, isotropy, orthotropy, anisotropy), like metals, human bones, human tissues, wood-based materials, plastics, or composites $[7,8]$.

Other significant advantage of this system consists in its potential, allowing a very high-accurate analysis (practically pixel-by-pixel) of the investigated surface, which cannot be guaranteed in the classical experimental methods. This valutation accuracy can be improved by selecting a zoomed viewing area, respectively using higher accuracy cameras [7].

Also, the software of VIC-3D offers the facility of monitoring the obtained results, either in colour raph (similarly with the FEM analysis results), either can be exported in Excel-files, destined for drawing-up several useful graphs. this study these advantages of this method makes it to be of great aplicability and interest in the future [9-11]. This method tends to be one of great applicability, and widely used for verification of input datas used in FEM experiments [12].

We decided to study several cases according to the number of the inserted implants and the distances between them. There were inserted collinearly 3 dental implants with exactly the same geometrical parameters, but with different distances between them. There was a distance of $6 \mathrm{~mm}$ between the implant no. 1 and implant no. 2 , and a distance of $15.5 \mathrm{~mm}$ between implant no. 1 and implant no 3 . In the first case we investigated the vertical displacement- field of the fixing substrate in the axis of implant no. 2 following the application of compressive force (Figure 1, Figure 2). Next, the same implant (no. 2) was solicited together with the implant no. 1 (Figure 3). Lastly implant no. 1 and implant no. 3 both were subjected to compressive forces (Figure 4). The displacements of the substrate were studied in the axis of the implants at 3 different levels: cervical, inter-medial and apical.

Data of the vertical displacemant-field were extracted from excel-files.
In order to calculate the average of the vertical displacements at the cervical intermediar and apical zone of the substrate, we used the statistical software Graph Pad Prism 5. For the determination of statistically significant differences we used the One Way Anova test and subsequently the Tukey test.

\section{Results}

The average value of the micro- dislocations at different levels of the dental implants are presented in tables no. I, II and III.

We observed significant differences between the displacements at the cervical and apical levels of the dental implant no. 2.

The differences between the vertical displacements of the fixating substrate in the axis of the implant at the cervical zone(s) in case I and case II are statistically not significant. Given case no. II., there were no significant differences between micro- movements measured at different levels of the axis of implant no. 1 and no.2.

There are significant differences regarding the displacements in the cervical zone of the implants in case no. II and case no. III. Given case no. III., there were no significant differences between displacements measured at different levels of the axis of implant no. 1 and no. 3 .

\section{Discussion}

In each case the most significant vertical displacements of the implant surrounding substrate were found at the cervical zone of the dental implant, and gradually lessen through the apical zone. Other experimental studies based on finite element analysis (FEM) and Digital Image Correlation (DIC) analysis got same results [7,13-15]. Some authors conducting FEM experiments found that under certain levels of bone thickness $d$ the insertion of dental implants is contraindicatefrom biomechanical point of view [12]. The most significant vertical displacements were observed at the cervical zone of the implant no. 2 when it was compressed alone. In this case we observed statisti-

Table I. The average value of the micro- dislocations at different levels of the dental implant no. 2, case I

\begin{tabular}{lcc}
\hline $\begin{array}{l}\text { Cervical zone }[\mathrm{mm}] \\
\text { Implant no.2 }\end{array}$ & $\begin{array}{c}\text { Intermediar zone }[\mathrm{mm}] \\
\text { Implant no.2 }\end{array}$ & $\begin{array}{c}\text { Apical zone }[\mathrm{mm}] \\
\text { Implant no.2 }\end{array}$ \\
\hline-0.01736 & -0.01537 & -0.01145 \\
\hline
\end{tabular}

Table II. The average of the displacements at different levels of the dental implants in case II

\begin{tabular}{|c|c|c|c|c|c|}
\hline $\begin{array}{l}\text { Cervical zone } \\
\text { Implant no. } 1\end{array}$ & $\begin{array}{l}\text { Cervical zone } \\
\text { Implant no. } 2\end{array}$ & $\begin{array}{l}\text { Intermediar zone } \\
\text { Implant no.1 }\end{array}$ & $\begin{array}{l}\text { Intermediar zone } \\
\text { Implant no.2 }\end{array}$ & $\begin{array}{l}\text { Apical zone } \\
\text { Implant no. } 1\end{array}$ & $\begin{array}{l}\text { Apical zone } \\
\text { Implant no.2 }\end{array}$ \\
\hline-0.01337 & -0.01562 & -0.01289 & -0.01462 & -0.01072 & -0.01243 \\
\hline
\end{tabular}

Table III. The average of the displacements at different levels of the dental implants in case III. (implant no. 1 and implant no. 3 both were subjected to compressive forces)

\begin{tabular}{|c|c|c|c|c|c|}
\hline $\begin{array}{c}\text { Cervical zone Implant } \\
\text { no. } 1\end{array}$ & $\begin{array}{c}\text { Cervical zone Implant } \\
\text { no. } 3\end{array}$ & $\begin{array}{l}\text { Intermediar zone } \\
\text { Implant no. } 1\end{array}$ & $\begin{array}{l}\text { Intermediar zone } \\
\text { Implant no.3 }\end{array}$ & $\begin{array}{c}\text { Apical zone Implant } \\
\text { no.1 }\end{array}$ & Apical zone Implant no.3 \\
\hline-0.008511635 & $-0,005555412$ & -0.008036306 & $-0,005412987$ & $-0,006481656$ & $-0,00477962$ \\
\hline
\end{tabular}




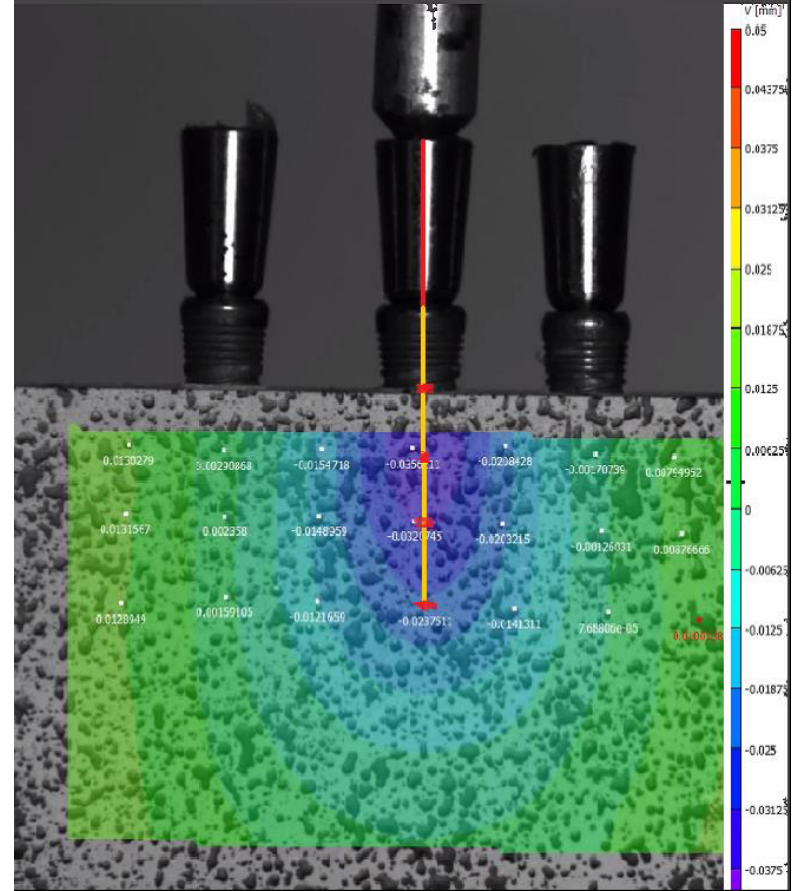

Fig. 1. From left to right implant no.3, 2, 1.

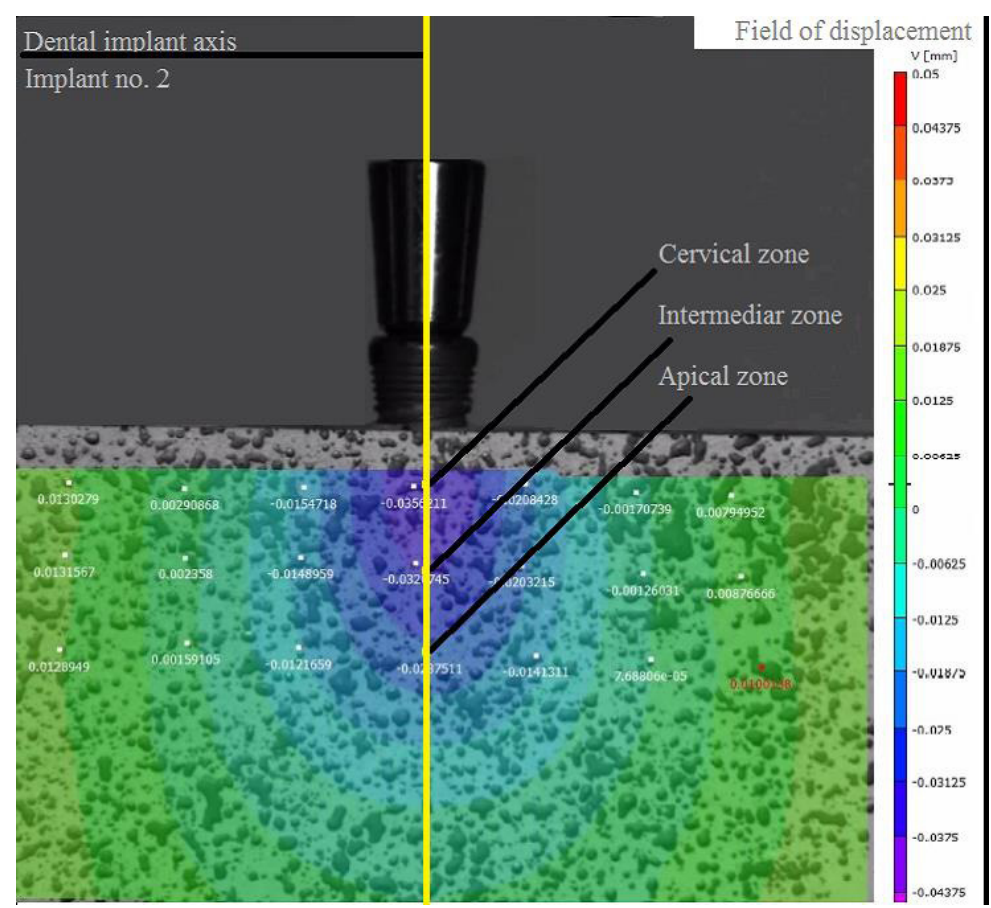

Fig. 2. Vertical displacements of the fixing substrate when loading implant no.2 (case I.)

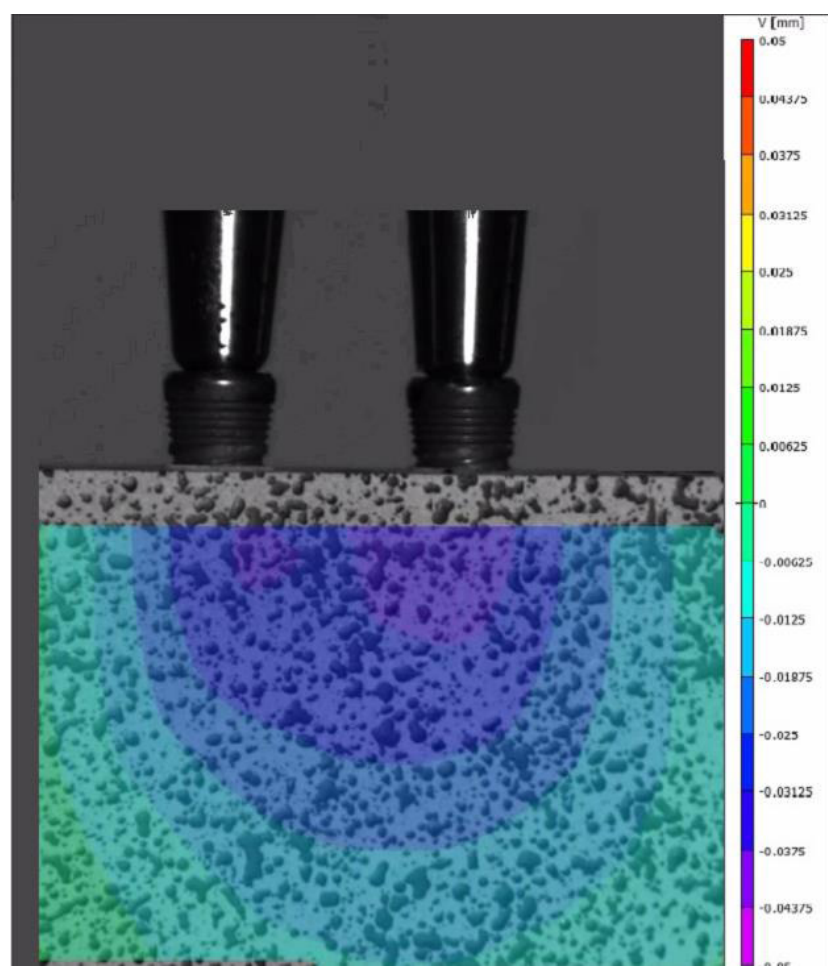

Fig. 3. The same implant (no. 2) was solicited together with the implant no. 1.

cally significant differences between the cervical and apical zones. The majority of displacements could be found at the cervical zone of the implant, this being a critical zone regarding the overload of the fixating substrate. The same decreasing trend from the cervical towards the apical zone were found in case no. II and case no. III but the average of the displacements were smaller than in case no. I. The displacements and their differences at the cervical, intermediar and apical zones were smaller and statistically not significant.

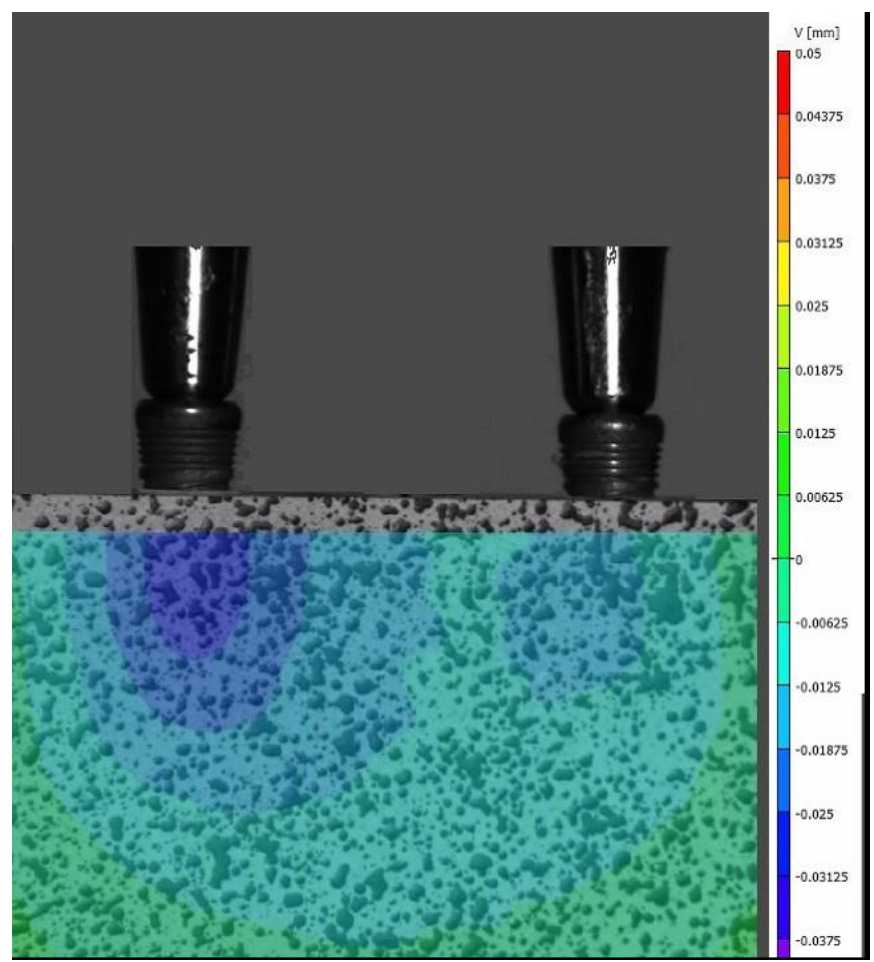

Fig. 4. Implant no. 1 and implant no. 3 both were subjected to compressive forces.

We conclude that the transmission of the compressive forces to the fixating substrate was more optimal and more equal in case no. II than in case no. I. Due to the increase in the distance between the implants (case no. III), force distribution has got more optimal than in case no. I or case no. II. This fact is also highlighted by the finding that there are significant differences of the average displacements of the fixating substrate at the cervical zones in cases no. II and no. III, but the average value of the displacements are smaller in case no. III than in case no. II. Neither in case 
no. II and no. III were found significantly different displacements at the given vertical levels inside the implant fixing substrate.

\section{Conclusion}

Regardless of the deterioration grade of the fixing substrate, the most significant displacements can be found in the cervical zone of the dental implant, and gradually lessen towards the apical zone. Biomechanically, a single dental implant is less advantageous than two dental implants next to each other, when subjected to compressive force. Increasing the distance between two implants, the distribution of the forces inside the fixing substrate is more optimal than in case of two implants situated at a smaller distance between them.

\section{References}

1. Lars W, Lindquist D, Birger R, Gunnar E, Carlsson D. Bone resorption around fixtures in edentulous patients treated with mandibular fixed tissueintegrated prostheses. Journal of Prosthetic Dentistry. 1988;59:59-63.

2. Brunski JB. The Influence of Force, Motion, and Related Quantities on the Response of Bone to Implants in Non-Cemented Total Hip Arthroplasty (R. Fitzgerald, Jr., ed.). New York. Raven Press Ltd. 1988;721.

3. Szmukler-Moncler S, Piattelli A, Favero GA, Dubruille JH. (2000). Considerations preliminary to the application of early and immediate loading protocols in dental implantology. Clin Oral Implants Res. 2000;11:12-25.
4. Shigeto K, Hiroto S, Masayoshi $\mathrm{Y}$, et al. Changes in Bone Metabolism Around Osseointegrated Implants Under Loading. Implant Dentistry- The Most Promising Discipline of Dentistry. Croatia. InTech. 2011;203-218.

5. Divinyi T. Oralis Implantologia. Budapest. Semmelweis Kiado. 2007:123125.

6. Szava I. Rezistența Materialelor. Brasov. Editura Universității Transilvania din Brașov. 1999; 162- 168.

7. Szava D, Bogozi B, Galfi B, Szava I, Ionescu RD. Dental Implants Analysis by Means of Video Image Correlation Method.Rev. Procedia Technology ISSN:2212-0173.

8. Khan A, Wang X. Strain Measurements and Stress Analysis. New Jersey. Prentice-Hall Inc. 2001;257- 261.

9. Assunção WG, Barão VA, Tabata LF, Gomes EA, Delben JA. Biomechanics studies in dentistry: bioengineering applied in oral implantology. J Craniofac Surg. 2009 Jul;20:1173-1177.

10. VIC-3D, Testing Guide, Correlated Solutions, ISI-Sys GmbH, USA. 2010.

11. VIC-3D, Reference Manual, Correlated Solutions, ISI-Sys GmbH, USA, Germany. 2010.

12. Szava D, Bogozi B, Galfi B, Szava I. Video image correlation method involved in dental implants' analysis. Journal of Industrial Design and Engineering Graphics Papers of the International Conference on History and Technology at the Black Sea region ISTM 2014, Constanta, 2014;109- 112.

13. Okumura N, Stegaroiu R, Kitamura E, Kurokawa, Nomura S. Influence of maxillary cortical bone thickness, implant design and implant diameter on stress around implants: A three-dimensional finite element analysis. J Prosthodont Res. 2010;54:133-142.

14. Qian L, Todo M, Matsushita Y, Koyano K. Effects of Implant Diameter, Insertion Depth, and Loading Angle on Stress/Strain Fields in Implant/ Jawbone Systems: Finite Element Analysis. Int J Oral Maxillofac Implants. 2009;24:877-886.

15. Morita Y, Qian L, Todo M, Matsushita Y, Arakawa K. Strain Distribution around Dental Implants in Cortical/Cancellous Bone Models using DIC Method. Applied Mechanics and Materials. 2010;73-77. 